\title{
Barriers to safe hot tap water: results from a national study of New Zealand plumbers
}

\author{
C Jaye, J C Simpson, J D Langley
}

\begin{abstract}
Introduction-Many countries still have unacceptably high hospitalizations and deaths from scalds from hot tap water. Prevention strategies implemented in some countries may not work in others. Legislation aimed at changing environments that are conducive to hot tap water scalds may not be effective in many situations for a number of reasons, including lack of acceptability and practicality.

Method-A qualitative study of a purposefully selected group of craftsman plumbers across New Zealand was conducted using a structured format with open ended questions. The questionnaire was administered by telephone. Information was sought on the opinions, knowledge, and practice of these plumbers regarding hot tap water safety in homes.

Results-Several barriers to hot tap water safety in homes were identified by the plumbers. These included common characteristics of homes with unsafe hot tap water, such as hot water systems heated by solid fuel, and public ignorance of hot tap water safety. Other factors that emerged from the analysis included a lack of knowledge by plumbers of the hazards of hot tap water, as well as a lack of importance given to hot tap water safety in their plumbing practice. Shower performance and the threat to health posed by legionella were prioritized over the prevention of hot tap water scalds.

Conclusion-The findings of this study allow an understanding of the practical barriers to safe hot tap water and the context in which interventions have been applied, often unsuccessfully. This study suggests that plumbers can represent a barrier if they lack knowledge, skills, or commitment to hot tap water safety. Conversely, they represent a potential source of advocacy and practical expertise if well informed, skilled, and committed to hot tap water safety.

(Injury Prevention 2001;7:302-306)
\end{abstract}

Keywords: hot tap water scalds; legionella; antiscald campaigns; legislation

Injury caused by hot tap water affects the young, the elderly, and the disabled disproportionately. ${ }^{1-20}$ Various authors have identified issues surrounding hot tap water scalds, and reported on intervention programs aimed at reducing the incidence and severity of these scalds. ${ }^{21-39} \mathrm{~A}$ crucial factor is the temperature of the water. Many researchers have suggested that this must be targeted in any serious attempt to reduce the incidence and severity of hot tap water scalds because it is more practical to modify than any other factor. ${ }^{10353640}$ It has been suggested that while educational programs raise levels of awareness of the dangers of hot tap water in the community, they do not necessarily lead to the implementation of safe behaviors, or the modification of the physical environment. ${ }^{41-48}$

In several countries, pressure from various organizations has resulted in legislation aimed at reducing the temperature of hot tap water. ${ }^{49} 50$ New Zealand, for example, has a building code that requires all new and modified existing hot water systems to have hot water delivered to personal hygiene fixtures and appliances at a maximum temperature of $45^{\circ} \mathrm{C}$ in early childhood centers, schools, and old people's homes, and $55^{\circ} \mathrm{C}$ in all other buildings. It also requires that domestic hot water is stored at a minimum temperature of $60^{\circ} \mathrm{C}$ to prevent the growth of legionella bacteria, ${ }^{51}$ recommending that a tempering valve be used to control delivery temperatures. Tempering valves mix hot and cold water to achieve a lower delivery temperature than the storage temperature. ${ }^{52}$

Educational strategies, however, have not been particularly effective in New Zealand. ${ }^{48}$ One reason appears to be the variable quality and reliability in the technology used in domestic hot water systems. This may thwart legislative attempts to limit the delivery temperature of hot tap water. Faulty thermostats were specifically implicated in both US and New Zealand research that found more than $25 \%$ of households had hot water delivered to the tap at temperatures exceeding that at which the cylinder thermostat was set. ${ }^{48} 53-55$

In addition to addressing such technical problems, Moller suggested that improving domestic hot tap water safety would require collaboration between public health workers, burns associations, local government building and health inspectors, parents of young children, and plumbers. ${ }^{40}$

In New Zealand plumbers are primarily responsible for the installation and modification of domestic hot water systems. They are, therefore, the gatekeepers of domestic hot tap water. Interventions that involve modification of hot water delivery in homes require the cooperation of plumbers.

Plumbers' perceptions and experience of barriers to the delivery of safe hot tap water have not been previously explored. In this paper we report the findings of a qualitative study that examined New Zealand plumbers' attitudes, knowledge, opinions, and professional practice with regards to hot tap water
Otago, PO Box 913

Dunedin, New Zealan

jean.simpson@ipru.otago.ac.nz 
safety. The findings from this study were not intended to be representative of all plumbers. Rather, the aim was to examine the views and experiences of plumbers operating in a variety of contexts to gain a comprehensive insight into why current legislation and interventions have had limited long term success in lowering the incidence of hot tap water scalds. A qualitative approach was deemed the most appropriate means of achieving this goal.

\section{Method}

Potential participants for this study were identified from a public list of national registered plumbers. A sample of 253 craftsman plumbers was purposively selected to reflect a range of plumbing environments: rural and urban, different geographical and climatic localities, and the opinions of employers, sole operators, and employees. "Craftsman plumbers" were selected because they are legally authorized to both carry out, and supervise, hot water installations and modifications in New Zealand. After a pilot study, it was estimated that as many as 135 interviews might need to be conducted before information redundancy would occur. However, in this study, this point was reached at approximately 100 interviews.

Personnel experienced in qualitative interviewing and briefed to the requirements of the project conducted telephone interviews with participants. Variability between interviewers was minimized by the structured and standardized format of the interview schedule. The items in these interviews canvassed responses on topics such as hot tap water temperatures in homes, the technical aspects of hot water systems in homes, knowledge of health and safety issues, and plumbing practice. The interviews were tape recorded and responses entered into Microsoft Excel spreadsheets. Analysis of the data was conducted using a thematic technique. ${ }^{56}$

At the completion of the interviewing phase, 111 plumbers had been interviewed, a response rate of $70 \%$ of those invited to participate by telephone, once those ineligible (retired, not working on domestic hot water systems, or not craftsman plumbers) were excluded. It was not possible to screen for eligibility before the selection of the sample.

\section{Results}

The raw data collected were grouped into the following themes: (1) plumbers' perceptions of the importance of hot tap water safety to clients; (2) plumbers' knowledge of hot tap water safety; (3) plumbing practice with respect to the above; (4) plumbers' perceptions of unsafe households with regards to hot tap water; and (5) plumbers' professional training and hot tap water safety.

(1) PLUMBERS' PERCEPTIONS OF THE IMPORTANCE OF HOT TAP WATER SAFETY TO CLIENTS

According to most respondents, the level of hot tap water safety awareness among the public was reasonably low. Most reported that their clients were unaware of the delivery temperature of their hot tap water. Few clients requested a specific temperature, and these clients were commonly the elderly, and those with young families. Although respondents reported that some clients did request that their thermostats be turned down, an equal number requested that thermostats be turned up, and in the case of the former, safety was rarely mentioned as a reason for the change. Satisfactory performance of hot water systems in volume, supply, temperature and pressure, cost of the job when plumbing work was done, and shower performance were perceived as higher priorities for clients than hot tap water safety.

\section{(2) PLUMBERS' KNOWLEDGE OF HOT TAP WATER} SAFETY

Feldman estimated that a child will be seriously scalded (receive full skin thickness burns) at $54^{\circ} \mathrm{C}$ after 10 seconds exposure, and at $60^{\circ} \mathrm{C}$ after a one second exposure. ${ }^{57}$ Respondents generally lacked knowledge about the relationship between the time taken to burn and temperature, especially the exponential relationship between these variables. Most participants were aware that children and the elderly were at higher risk of hot tap water scalds than were the general population. The majority of respondents, however, over-estimated the time required for a child to be seriously scalded at $55^{\circ} \mathrm{C}$ (rounded up from $54^{\circ} \mathrm{C}$ ), and their estimates of the time required for a child to be seriously scalded at $60^{\circ} \mathrm{C}$ were even more inaccurate. They were, however, generally aware that serious injury would occur in less time.

Legionella proved to be an important issue for many respondents. Approximately half of those interviewed thought it more important to control for bacteria such as legionella than to prevent the potential for hot tap water burns. For many respondents, the perceived health risks posed by legionella was the rationale for having hot water stored at very high temperatures.

\section{(3) PLUMBERS' PRACTICE WITH RESPECT TO HOT} TAP WATER SAFETY

Despite concern regarding legionella, nearly half of the respondents reported being satisfied with the legislated delivery temperature of $55^{\circ} \mathrm{C}$. Reasons given were hot tap water safety, and that this temperature represented a good balance between the need to control legionella and hot tap water safety. The few participants who were dissatisfied with this regulation reported that hot tap water at this temperature was not hot enough to satisfactorily clean dishes and laundry, and it limited the supply of hot water to a household.

The majority of participants did not routinely measure hot tap water delivery temperature after working on a domestic hot water system, preferring to trust the thermostat or tempering valve, if one was installed. There was some contradiction, however, since a number commented on the notorious unreliability of thermostats. 
Two thirds of the respondents reported that the New Zealand Building Code regulations for the delivery of hot tap water (introduced six years earlier) had changed the way they practised. Most reported that they encountered practical obstacles in modifying existing (usually older) domestic hot water systems. Few participants said they had never encountered practical difficulties. Technical difficulties were common, and included the installation of tempering valves on existing pipes, low pressure systems, and re-piping houses. Other less commonly noted difficulties included consumer resistance to tempering valves and the expense of modifications. Early models of tempering valves were reported to have a high failure rate. Half of the respondents reported that this failure was still a common barrier to achieving $55^{\circ} \mathrm{C}$ at the tap.

The majority of those interviewed perceived the public to be ignorant of the regulatory requirements, but the respondents themselves often lacked a comprehensive understanding. Although the majority of participants expressed a commitment to hot tap water safety, they generally did not report communicating this commitment to clients by, for example, adopting an advocacy role during the decision making negotiations that occur when hot water systems were installed or modified. The few who reported adopting an advocacy role for hot tap water safety, however, said that their suggestions for improvements were generally well received by their clients.

\section{(4) REPORTED CHARACTERISTICS OF HOUSES} WITH UNSAFE HOT TAP WATER

Respondents reported four primary characteristics of houses that they considered had unsafe hot tap water. These were the presence of hot water systems heated by solid fuel, particularly coal and wood burners ("wetbacks"); houses built before 1992 when the current regulations on hot tap water were enacted; householders of low socioeconomic status and living in poverty; and householder's ignorance of hot tap water safety. Respondents suggested that older homes were likely to have smaller hot water cylinders set at a higher temperature to compensate for small capacity, to not have tempering valves installed, to be inhabited by low income families who rented, and they were more likely to have "wetbacks". Landlords were viewed as being uncommitted to hot tap water safety because of the expense of modifying older hot water systems.

(5) PLUMBERS' PROFESSIONAL TRAINING

Over half the respondents had attended a professional plumbing qualification course, most often during their apprenticeship. Only a small number of the participants had completed this course since 1992 when the new legislation on delivery temperatures had been enacted. Although training seminars were run by manufacturers and the professional bodies, most respondents reported that they did not attend these because of time restraints, cost, the travel involved, or lack of interest. Most considered that they did not require further training on topics and techniques pertaining to hot water installations and repairs.

\section{Discussion}

These results have yielded valuable information on how domestic hot tap water delivery can be improved by addressing the knowledge and practice of plumbers. For example, the problem of faulty tempering valves was still used as a rationale for not installing these items on hot water systems unless legally obligated, despite the problem with the valves having been substantially resolved some years earlier.

Respondents identified a number of technological barriers to hot tap water safety and these support comments in previously unpublished reports. For example, hot tap water can be excessively hot due to: (a) faulty or inaccurate thermostats and tempering valves; (b) compensation for insufficient storage caused by undersized cylinders; and (c) uncontrolled hot tap water from hot water cylinders heated directly by solid fuel or solar systems. What the plumbers' responses emphasised in addition was the negative effect of using tempering valves on shower performance. Reducing the thermostat setting of the hot water cylinder (even if it was accurate) was not necessarily viewed as a practical solution. Although it might result in considerable energy savings, it represented a reduction of useful energy in storage and therefore a decrease in the amount of readily available hot water. This was often experienced by clients as a cold shower, which plumbers concluded reflected negatively on their expertise.

Another barrier lies in the legislation. Respondents were aware that there was no legal requirement for systems that existed before 1992 to meet building code standards unless they were being modified. Replacing an existing cylinder was not legally defined as a "modification" so this work did not need to comply with hot tap water safety regulations. ${ }^{52}$ It is likely that over $90 \%$ of homes in New Zealand were built before 1992 .

The socioeconomic barriers identified by plumbers included the inter-related variables of poverty and living in rental housing. Those with low incomes are most likely to live in rental properties. Landlords were not seen as being committed to hot tap water safety where the modification of an existing hot water system is voluntary and likely to be expensive. Even when they own their own homes, low income families often cannot afford this expense.

Another barrier to safe hot tap water is attitudinal. Respondents perceived that the public was unaware that its hot tap water was unsafe and preferred having very hot water for hygiene over hot tap water safety. This perception of clients' priorities probably reflected the plumbers' own attitudes and priorities. Plumbers in this study were committed to their clients, but keeping costs to a minimum and killing legionella was seen as more important than hot tap water safety. If plumbers do not see hot tap water safety as a priority issue, they will not 
advocate for it, nor seek solutions. The few respondents in this study who reported that they did advocate for hot tap water safety reported that their suggestions for improvements were generally well received by clients. This suggests that the barriers may lie more with the plumbers' rather than with the clients' attitudes.

Ensuring that all plumbers advocate safety may not be easy. Plumbers' professional training courses represent a potential opportunity for exposing them to, and examining them on, knowledge and skills related to hot tap water safety. The curriculum and training process for plumbers has changed in recent years, and now includes coursework on hot tap water safety. None of those craftsman plumbers sampled had trained under the new system, however, and few attended the regular professional courses for further training. One obvious obstacle to the ongoing training of craftsman plumbers was their general perception that they did not require upskilling. Theoretically, reaching plumbers through professional journals and manufacturers may help to raise the level of awareness and knowledge about hot tap water safety among plumbers. In practice, however, although mailed material certainly reaches plumbers, they do not necessarily read this material.

\section{Implications for prevention}

Environmental factors have been identified as the most practical to modify in any attempt to reduce the incidence of injury from hot tap water. The most obvious and pragmatic of these is to reduce the delivery temperature of hot tap water in domestic dwellings. In New Zealand, as elsewhere, intervention campaigns aimed at reducing the incidence of serious thermal injury from hot tap water depend on reaching households with information about the dangers of hot tap water and methods of reducing risk factors within the household, and the translation of this awareness into preventive action. This study confirms that plumbers, in particular, are the technical professionals with the potential to make domestic hot water systems as safe as practical.

Plumbers, as the specialists who install and modify domestic hot water systems, identified a number of inter-related variables that included technical problems, especially with older housing, poverty, wetbacks, and public ignorance as barriers to hot tap water safety. This study suggests that plumbers themselves can represent a barrier if they lack knowledge, skills, or commitment to hot tap water safety. Conversely, they represent a potential source of advocacy and practical expertise if well informed, skilled, and committed to hot tap water safety. Those in the fields of public health and injury prevention need to cultivate relationships with the technical professions at both the training and practice levels if effective long term solutions to hot tap water injuries are to be developed.

Funded by the Health Research Council of New Zealand.
Key points

- Some countries still have unacceptably high hospitalisations and deaths from hot tap water scalds, despite the implementation of prevention strategies.

- Plumbers are the key service providers for domestic hot water systems.

- A major barrier to safe hot water in the home is the lack of practical knowledge and understanding of the relevant safety issues amongst plumbers.

- Informed and committed plumbers can be powerful advocates for hot tap water safety.

- Health promotion planners should cultivate relationships with technical professionals to develop effective long term solutions to domestic hot tap water injuries.

1 Katcher ML. Scald burns from hot tap water. $f A M A$ 1981;246:1219-22.

2 East MK, Jones CA, Feller I, et al. Epidemiology of burns in children. In: Carvajal HF, ed. Burns in children: pediatric burn managen

3 Darko DF, Wachtel TL, Ward HW, et al. Analysis of 585 burn patients hospitalised over a 6-year period. Part III: psychosocial data. Burns 1986;12:395-401.

4 Ostrow LB, Bongard FS, Stacks ST, et al. Burns in the elderly. Am Fam Physician 1987;35:149-54.

5 Murray JP. A study of the prevention of hot tapwater burns. Murray JP. A study of the
Burns 1988;14:185-93.

6 Feldman KW, Clarren SK, McLaughlin JF. Tap water burns in handicapped children. Pediatrics 1981;67:560-2.

7 Langley J, Tobin P. Childhood burns. N Z Med $\mathcal{F}$ 1983;86:681-4.

8 Waller AE, Marshall SW, Langley JD. Adult thermal injuries in New Zealand resulting in death and hospitalization. Burns 1998;24:245-51.

9 Thomson HG, Shore B. The bathtub burn - a pediatric disaster. Canadian Fournal of Surgery 1971;14:399-401.

10 Langley J, Dodge J, Silva PA. Scalds to preschool children. NZ Med f 1981;93:84-7.

11 Pegg SP, Gregory JJ, Hogan PG, et al. Burns in childhood: an epidemiological study. Aust $N Z$ F Surg 1978;48:365-73. McLoughlin E, Crawford JD. Types of burn injuries. Pediatr Clin North Am 1985;32:61-75.

13 Rossignol AM, Locke JA, Burke JF. Pediatric burn injuries in New England, USA. Burns 1990;16:41-8.

14 Adams LE, Purdue GF, Hunt JL. Tap-water scald burns: Adams LE, Purdue GF, Hunt JL. Tap-water scald burns:
awareness is not the problem. F Burn Care Rehabil 1991;12: awaren.

15 Walker AR. Fatal tapwater scald burns in the USA, 1979-86. Burns 1990;16:49-52.

16 Baux S, Mimoun M, Lioret H, et al. Burns in the elderly. Burns 1989; 15:239-40

17 Herd BM, Herd AN, Tanner NSB. Burns to the elderly: a reappraisal. Br F Plast Surg 1987;40:278-82.

8 Hong QL, Zamboni W, Eriksson E, et al. Burns in patients under 2 and over 70 years of age. Ann Plast Surg 1986;17: $39-44$.

19 Hammond J, Ward CG. Burns in octogenarians. South Med 7 1991;84:1316-19.

20 Tejerina C, Reig A, Codina J, et al. Burns in patients over 60 years old: epidemiology and mortality. Burns 1992;18:149 52.

21 Petro JA, Belger D, Salzberg CA, et al. Burn accidents and the elderly: what is happening and how to prevent it. Geriatrics 1989;44:26-48.

22 Williams EE, Griffiths TA. Psychological consequences of burn injury. Burns 1991;17:478-80.

23 Hamilton J. Hospitalizations due to tap water scalds: 1983-1987. (Master of Public Health.) Minneapolis: 1983-1987. (Master of Public
University of Minnesota, 1990.

24 Feldman KW, Schaller RT, Feldman JA, et al. Tap water scalds in children. Pediatrics 1978;62:1-7.

25 Waller AE, Marshall SW. Childhood thermal injuries in New Zealand resulting in death and hospitalization. Burns 1993;19:371-6.

26 Molinaro JR. The social fate of children disfigured by burns. Am F Psychiatry 1978;135:979-80.

27 Zamboni WA, Cassidy M, Eriksson E. Hand burns in children under 5 years of age. Burns 1987;13:476-83.

28 Herd AN, Widdowson P, Tanner NSB. Scalds in the very young: prevention or cure? Burns 1986;12:246-9.

29 Gordon PG, Ramsay GC. A survey of thermal injuries to children in Australia. Aust Fam Physician 1986;15:1222-9.

30 Simpson J, Wright C. Scalds. Dunedin: Injury Prevention Simpson J, Wright C. Scalds. Dunedin:
Research Unit, Fact Sheet No 10, 1997.

31 Slater H, Gaisford JC. Burns in older patients. F Am Geriatr Soc 1981;29:74-6. 
32 Yiacoumettis A, Roberts $M$. An analysis of burns in children. Burns 1977;3:195-201.

33 Heaton PAI. The pattern of burn injuries in childhood. $N Z$ Med F 1989;102:584-6.

34 Borland BL. Prevention of childhood burns: conclusions drawn from an epidemiological study. Clin Pediatr (Phila) 1967;6:693-5.

35 Larson A. Prevention of tap water scald injuries (in press).

36 Feck G, Baptiste MS, Tate CL. Burn injuries: epidemiology and prevention. Accid Anal Prev 1979;11:129-36.

37 New South Wales Department of Health. The impact of turning down electric hot water systems. Scalds Prevention Campaign Bulletin September 1994(3):3.

38 Shwarz DF, Grisso JA, Miles C, et al. An injury prevention program in an urban african-American community. $A m \mathcal{F}$ Public Health 1993;83:675-80

39 Katcher ML. Tap water scald prevention: it's time for a worldwide effort. Inj Prev 1998;4:167-9.

40 Moller J. Strategic Perspectives in Burn and Scald Prevention. Paper presented at the Second World ConferPrevention. Paper presented at the Second World Conference 1993.

41 McNair A. Awareness and prevention of burns among caregivers of preschool children. Report to the Accident Compensation Corporation: Wellington, 1990

42 Standards. Legionnaire's disease. Standards 1993;39(3):11.

43 Andersen RD, Lauer BA, Fraser DW, et al. Infections with Legionella pneumophila in children. F Infect Dis 1981;143: 386-90.

44 Dialogue Consultants Ltd. Thermal injury prevention. Report to the Accident Compensation Corporation: Wellington, 1989.

45 McLoughlin E, Vince CJ, Lee AM, et al. Project Burn Prevention: outcome and implications. Am f Public Health $1982 ; 72: 241-52$.
46 MacKay AM, Rothman KJ. The incidence and severity of burn injuries following Project Burn Evaluation. Am F Pubic Health 1982;72:248-52.

47 New South Wales Health Department. "Hot Water Burns Like Fire"-the NSW Scalds Prevention Campaign, phases one and two, 1992-1994. Final report. Sydney: NSW Health Department, 1999.

48 Waller AE, Clarke JA, Langley JD. An evaluation of a program to reduce home hot tap water temperatures. Aust 7 Public Health 1993;17:116-23.

49 Erdmann TC, Feldman KW, Rivara FP, et al. Tap water burn prevention: the effect of legislation. Pediatrics 1991;88:572-7.

50 Yeoh C, Nixon JW, Dickson W, et al. Patterns of scald injuries. Arch Dis Child 1994;71:156-8.

51 AS/NZS 3500.4.2: 1997 National plumbing and drainage. Part 4.2: hot water supply-acceptable solutions.

52 Building Industry Authority. The New Zealand building code handbook and approved documents (1995). 2nd Ed. Wellington, New Zealand: Building Industry Authority, 1995.

53 Webne SL, Kaplan BJ. Preventing tap water scalds: do consumers change their preset thermostats? Am F Public Health 1993;83:1469-70.

54 Dickson N, Martin M, Waller AE. Hot water temperature in Dunedin homes with preschool children. N Z Med f 1990; 103:452-4.

55 Clarke JA, Waller AE, Marshall SW, et al. Barriers to the reduction of domestic hot water temperatures. Safety Science 1995;18:181-92.

56 Crabtree BF, Miller WL. Doing qualitative research. London: Sage, 1992.

57 Feldman KW. Help needed on hot water burns. Pediatrics 1983;71:145-6.

\section{New York votes to ban phones held by drivers}

New York has become the US first state to ban talking on a hand-held cellular telephone while driving, under a bill that the Assembly passed recently. The bill passed the Assembly by a 125 to 19 vote. Its passage is the latest development in a growing national movement against what many people perceive as a new hazard in this age of wireless communication: drivers causing accidents because their minds are focused on telephone conversations or their hands are fumbling with small phones.

Similar bans have been proposed in 41 other states in the last two and a half years, but those have so far failed to pass. Most wireless telephone companies have lobbied hard against the measures, arguing that telephones are just one of several distractions that cause accidents, and that education campaigns would be more effective than laws.

The bill does not ban talking on the telephone in a car, but makes it a traffic violation to raise a handset to the ear and have a conversation. Talking with the aid of a headset or speakerphone would be allowed.

The ban took effect on November 1, though violators got only warnings from the police until December 1. After that, a judge could impose a fine of up to $\$ 100$. Until March, judges may also waive fines if a driver can prove that he or she has bought a headset or speakerphone.

The new law would direct state traffic officials to analyze the causes of accidents over the next four years to determine if cell phones do cause accidents. It would also exempt people who use their telephones in emergencies to call police or fire departments or other authorities.

The vote was a personal victory for Assemblyman Felix Ortiz, a Brooklyn Democrat who has championed such a ban every year since 1996. Mr Ortiz said he was inspired to introduce the first bill after witnessing an accident caused by a woman on a telephone.

Even supporters of the ban acknowledge that there is scant empirical evidence linking hand-held telephones to accidents. In 1997, The New England fournal of Medicine published a study suggesting that a person who regularly used a telephone while driving was four times more likely to have an accident than a driver who did not. But an American Automobile Association study, which looked at 32303 traffic accidents between 1995 and 1999, found that fiddling with a radio or tape player caused far more accidents than talking on the phone. Only 42 of the accidents could be traced to phone use. "It is absolutely a distraction", Stephanie Faul, a spokeswoman for the AAA Foundation for Traffic Safety. "The question is, how often does it cause accidents? From our data, it seemed to cause a small percentage of the crashes".

(From NYTimes.com, June 2001. Contributed by Anara Guard) 